\title{
Sustainable Development Goals and Visualizing Small Island Developing States
}

\author{
Jessica Gosling-Goldsmith ${ }^{\text {a, } * \text {, Britta Ricker }}{ }^{\text {a }}$, Menno Jan Kraak ${ }^{\text {a }}$ \\ ${ }^{a}$ Faculty of Geoinformation Science and Earth Observation, University of Twente, goslinggol36984@alumni.itc.nl \\ * Corresponding author
}

\begin{abstract}
Small-scale thematic maps help to visualize world-wide data, yet small nations can be difficult to discern or are omitted completely. This occurs for small island developing states (SIDS), a group of more than fifty states recognized by the United Nations for their social, economic and environmental vulnerabilities. Through this study we proposed and evaluated alternative maps to increase the perceptibility of SIDS using indicator data of the Sustainable Development Goals (SDGs). These goals link social, economic and environmental objectives to achieve globally by 2030. Five cartographic solutions were refined to one based on input from two focus groups of geoinformation scientists and cartographers as well as an interview with a SIDS resident. The selected map was evaluated by a larger audience in an online survey. Most survey participants had some experience with SIDS, worked in international organizations and/or had graduate-level degrees in a geographic-related science. While recommendations for improvement were provided, nearly seventy percent of the participants agreed the presented design was appropriate to represent SIDS in choropleth world maps.
\end{abstract}

Keywords: Sustainable Development Goals (SDGs), small island developing states (SIDS), projections, map design

\section{Introduction}

The United Nations (UN) members states established the Sustainable Development Goals (SDGs) for the well-being of all people and the planet. SDGs address social, economic and environmental objectives and are measured by 169 targets and 232 indicators to reach by 2030 . The indicators of the SDGs are portrayed in world maps that appear in paper reports and online publications. Due to the small scale of these maps the coastlines and boundaries are necessarily generalized. This is a good cartographic habit to keep the maps readable but is problematic for small countries and especially the small island developing states (SIDS). This last category might actually disappear completely due to the constraints used during generalization. When SIDS survive the generalization process, they are challenging to distinguish. This makes it difficult if not impossible to derive their qualitative or quantitative indicator information, if available at all, from the maps. In this paper we suggest solutions for the disappearing small island developing states.

The United Nations designated the category of small island developing states in 1992, acknowledging their "social, economic and environmental vulnerabilities" (OHRLLS UN, 2018). SIDS are vulnerable to natural disasters, climate change and extreme weather which can be compounded by their possible economic vulnerability and/or lack of coping capacity (World Bank, 2017). As noted by the UN, "Probabilistic models show that small island developing states are expected to bear disproportionately large economic losses attributed to disasters" (DESA - UN, 2018a).

The Alliance of Small Island States (AOSIS) estimates that SIDS represent five percent of the global population (AOSIS, 2018). Small island developing states vary in their spatial configuration, from a single island to "highly fragmented multiple islands" (Nurse et al., 2014). For example, the Seychelles are comprised of 115 islands and the Solomon Islands contain nearly 1,000 islands (EverestPhillips, 2014). The small size of the country and often large distances to neighboring countries creates challenges and specific vulnerabilities for SIDS (Pelling \& Uitto, 2001). This study focused on visualizing the 52 small island developing states recognized by both the UN Statistics Division and the UN Sustainable Development Goals Platform at the time of writing, in the middle of 2018 (DESA - UN, 2018b; UNSD, 2018) (Figure 1). Based on UN designations, the SIDS regions identified were: 1) Atlantic Ocean, 2) Caribbean Sea, 3) Indian Ocean and 4) Pacific Ocean (including South China Sea).

While the UN database of SDG indicators (https://unstats.un.org/sdgs/indicators/database)

designates SIDS as a separate group, the data for SIDS are often unavailable. The dataset selected for this study was Indicator 1.1.1 Proportion of population below the international poverty line (Goal 1, Target 1). It contained 2016 data available for 138 countries of the $193 \mathrm{UN}$ member states, including 21 of the 52 SIDS across 
geographic regions, and as such gave a good representation of data at hand.

\section{Visualization}

The aim of this study was to identify the optimal projection, map layout and symbolization for the representation of SIDS in static world maps. Maps were designed for print publication on landscape A3 paper (42.0 $\mathrm{x} 29.7 \mathrm{~cm})$. The location and design of the title and legend were consistent while other elements, such as the projection, addition of insets and island symbolization varied.

In considering the choropleth color values for the map, typically six or seven values of red are discernible (Kraak \& Ormeling, 2003). To standardize the color scale, a red color scheme was selected through ColorBrewer in consideration of those with color vision deficiencies. Five classes were created and a gray value represented unavailable data.

As small islands typically disappear on small-scale static maps, symbols were used to enhance the perceptibility of SIDS and their choropleth values. Circular point symbols and ISO-alpha3 codes were tested to represent SIDS. Circles offered a "smooth visual impression" and are "more compact" compared to squares or triangles (Krygier \& Wood, 2005, p.215). ISO-alpha3 codes are unique, three-letter codes to identify each country maintained by the International Organization for Standardization. This alternative to circles gave the possibility to perceive the choropleth values as well as identify the SIDS in a dense space.

The study started with five maps, referred to as Maps A-E, to explore projection, page layout and symbolization (Figure 2). Maps A-C used the Winkel-Tripel projection (which minimizes distortion in angle, area and distance) and circular point symbols to represent SIDS. The central meridian of $48^{\circ} \mathrm{E}$ preserved the Pacific islands in one region and leader lines identified Caribbean island locations at this scale. Map A filled the extent of the page with one world map while Maps B and C reduced the world map to make room to show SIDS regions at a larger scale and improve the perceptibility of these islands. Map $B$ included rectangular insets of the SIDS regions and Map $\mathrm{C}$ used circular insets inspired by magnifying lenses. Map D applied circular point symbols to represent SIDS and used the Interrupted Goode Homolosine projection focused on oceans and centered in the Pacific at $160^{\circ} \mathrm{W}$. The Interrupted Goode Homolosine is an equal area projection ideal for statistical data and offered the potential to concentrate on oceans, emphasizing the distribution of SIDS. As in Map A, the Caribbean islands in Maps D and E were identified with leader lines. Map E centered the Mercator projection at $48^{\circ} \mathrm{E}$. Mercator is less suitable for statistical data but commonly used in web maps. It was included to test a familiar projection with the less familiar symbolization of ISO-alpha3 codes.

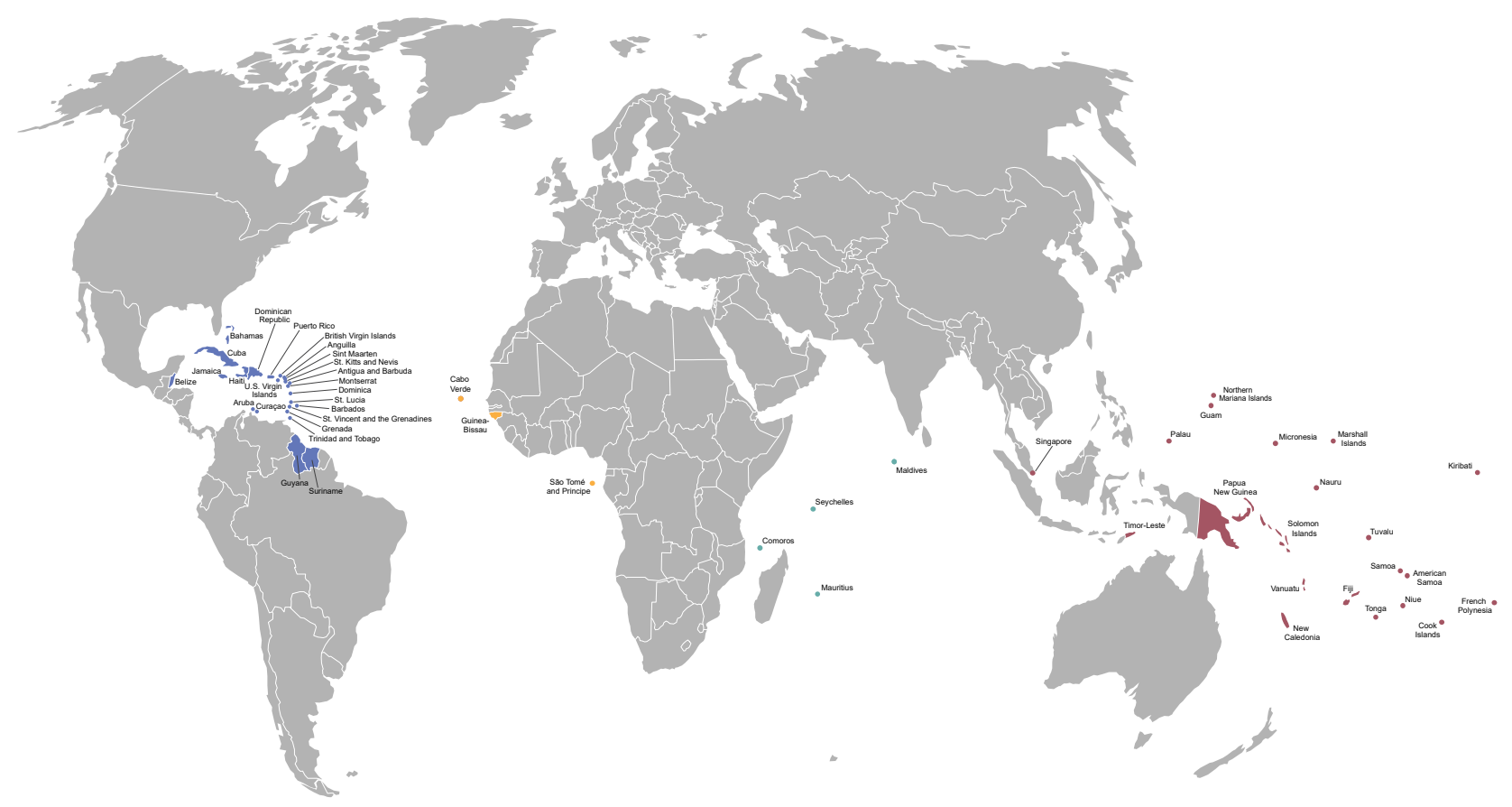

Figure 1. Map of 52 small island developing states. Recreated from Osiris, 2013. 


\section{Mapping the \\ Small Island Developing States}

SDG Indicator 1.1.1 Proportion of population below the international poverty line (2016)

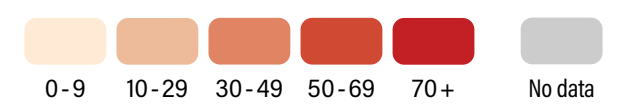

The boundaries and names shown and the designations used on this map do not imply official endorsement or acceptance.

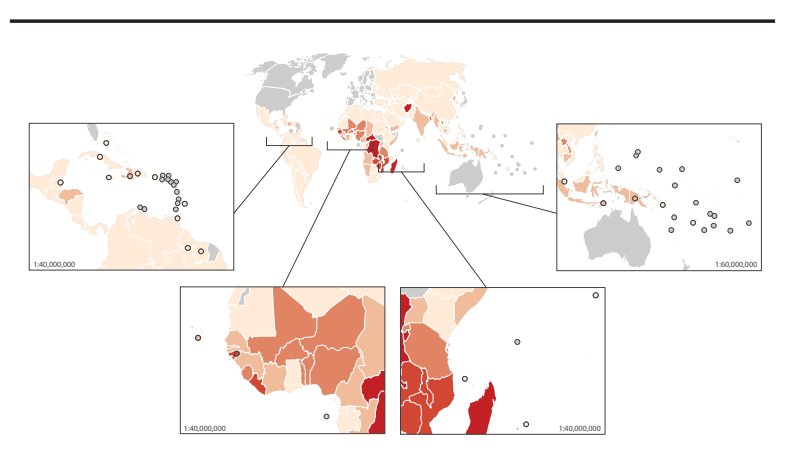

B
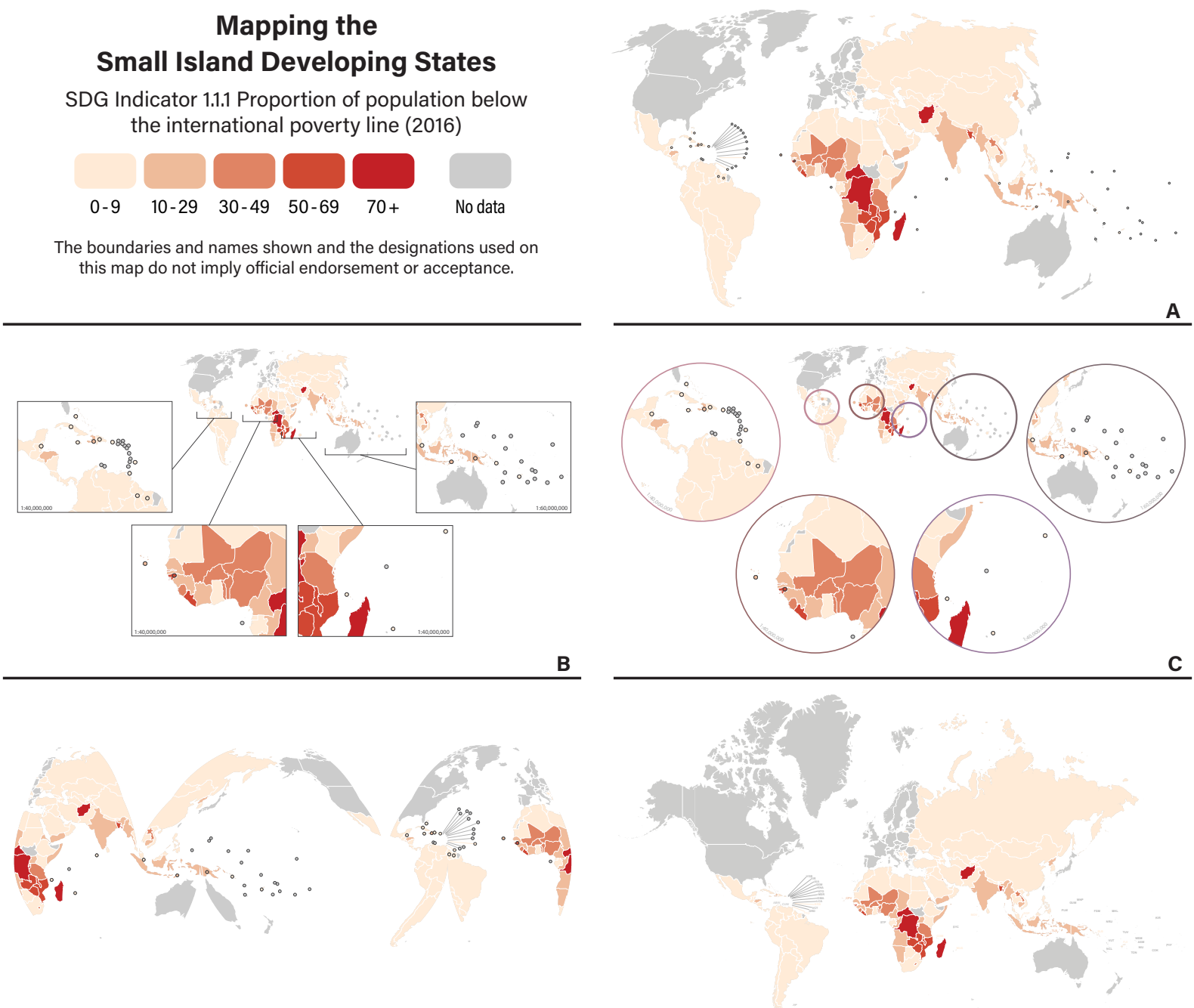

D

Figure 2. Five maps visualizing small island developing states. Map A uses the Winkel-Tripel projection and points to represent SIDS. Map B uses the Winkel-Tripel projection with points and insets. Map C uses the Winkel-Tripel projection with points and circular lenses. Map D uses the Interrupted Goode Homolosine projection and points. Map E uses the Mercator projection and ISO-alpha3 codes to represent SIDS. 


\section{Evaluation}

\subsection{Focus groups and interview}

The design revision process included two focus groups of geoinformation scientists and cartographers, and an interview with a resident of a small island developing state to identify map preferences. This led to a final map to be evaluated by a larger online audience (Table 1). This method sought to improve the visualization before the online evaluation to prevent survey fatigue caused by reviewing multiple maps in a single survey.

\begin{tabular}{lccc}
\hline Method & $\begin{array}{c}\text { Number of } \\
\text { participants }\end{array}$ & Date & $\begin{array}{c}\text { Number } \\
\text { of maps }\end{array}$ \\
\hline Focus Group 1 & 4 & 5 July 2018 & 5 \\
Focus Group 2 & 6 & 12 July 2018 & 2 \\
Interview with & 1 & 13 July 2018 & 1 \\
SIDS resident & & 24 July to 14 & 1 \\
Online Survey & 94 & August 2018 & \\
\hline
\end{tabular}

Table 1. Method to evaluate visualizations.

Focus Group 1 consisted of a Ph.D. student and staff of the Geoinformation Processing Department at the ITC Faculty of Geo-Information Science and Earth Observation at the University of Twente. The participants were introduced to the five printed maps one-by-one. Once all five maps were available to see, participants were asked how well each map visualized the global distribution of data and how easy it was to see data values for Caribbean islands. The conversation then moved to preferences of each visualization and whether it was appropriate to communicate SIDS data.

Participants in Focus Group 2 included an MSc. Cartography student and five cartography-related staff at ITC. They were shown two maps, which were selected and revised based on comments from Focus Group 1. Participants were shown both maps and then asked to discuss preferences and recommendations for the visualizations.

After the focus groups, the preferred map was shown in an interview with a lifelong resident of a small island developing state who works as a communications professional at a multi-national consortium of states in the Caribbean. This was to gain insight from someone living on a small island developing state. Following the interview, an online survey was administered to collect feedback on the map from a large and diverse set of users, testing for effectiveness and satisfaction (Roth, Ross, \& MacEachren, 2015).

\subsection{Online survey}

Based on expert feedback from the focus groups and interview, one map was selected and revised for an online evaluation using SurveyMonkey (Figure 3). Geographicrelated scientists and representatives from international organizations and SIDS were recruited as participants using snowball sampling. Cartographers were contacted through the International Cartographic Association Commissions on Cognitive Issues in Geographic Information Visualization, Visual Analytics, and Use, Users and Usability Issues. Attempts to reach representatives from SIDS were made through emails to the Secretariat of the Pacific Regional Environment Programme (SPREP) and Caribbean Community (CARICOM).

Participants were asked about previous experience with print and web maps, designing maps and working at an international organization to capture multiple forms of expertise among participants (Kinkeldey et al., 2014). Contextual individual differences were requested, such as experience of small island states, including but not limited to SIDS identified in this study (Smith Mason et al., 2017). The map was evaluated for effectiveness and satisfaction, two of the three components of usability recommended by the International Organization for Standardization in ISO 9241-11. The objective assessment included identification and comparison questions at the elementary and general search levels, such as identifying and comparing the poverty rates of individual countries and estimating the regional and global poverty rates (Roth, 2013). After each series of questions, grouped by search levels, the effort it took to answer these questions was collected on a Likert scale (Kinkeldey, MacEachren, Riveiro, \& Schiewe, 2017). A subjective assessment was conducted in an open comments section after completing the map tasks. Users were asked to give feedback on the design, such as the color, projection and symbols.

An exit survey gathered demographic information, including educational experience in a geographic-related science as another form of expertise. All questions were optional to encourage responses to the survey.

\section{Results}

\subsection{Focus groups and interview}

Participants in Focus Group 1 noted that the magnified, circular views of island regions had immediately caught their attention in Map C (Figure 2). Map D (Figure 2) elicited lively debate due to the interrupted projection, yet most users thought it offered valuable emphasis on the small island developing states. Participants supported Map A (Figure 2), though were less animated when discussing it and questioned if it provided enough focus on the SIDS. While they liked the concept of Map B (Figure 2), it was similar and less captivating than Map C (Figure 2). The projection of Map E (Figure 2) was dismissed and the ISOalpha3 codes received mixed reviews because they were 


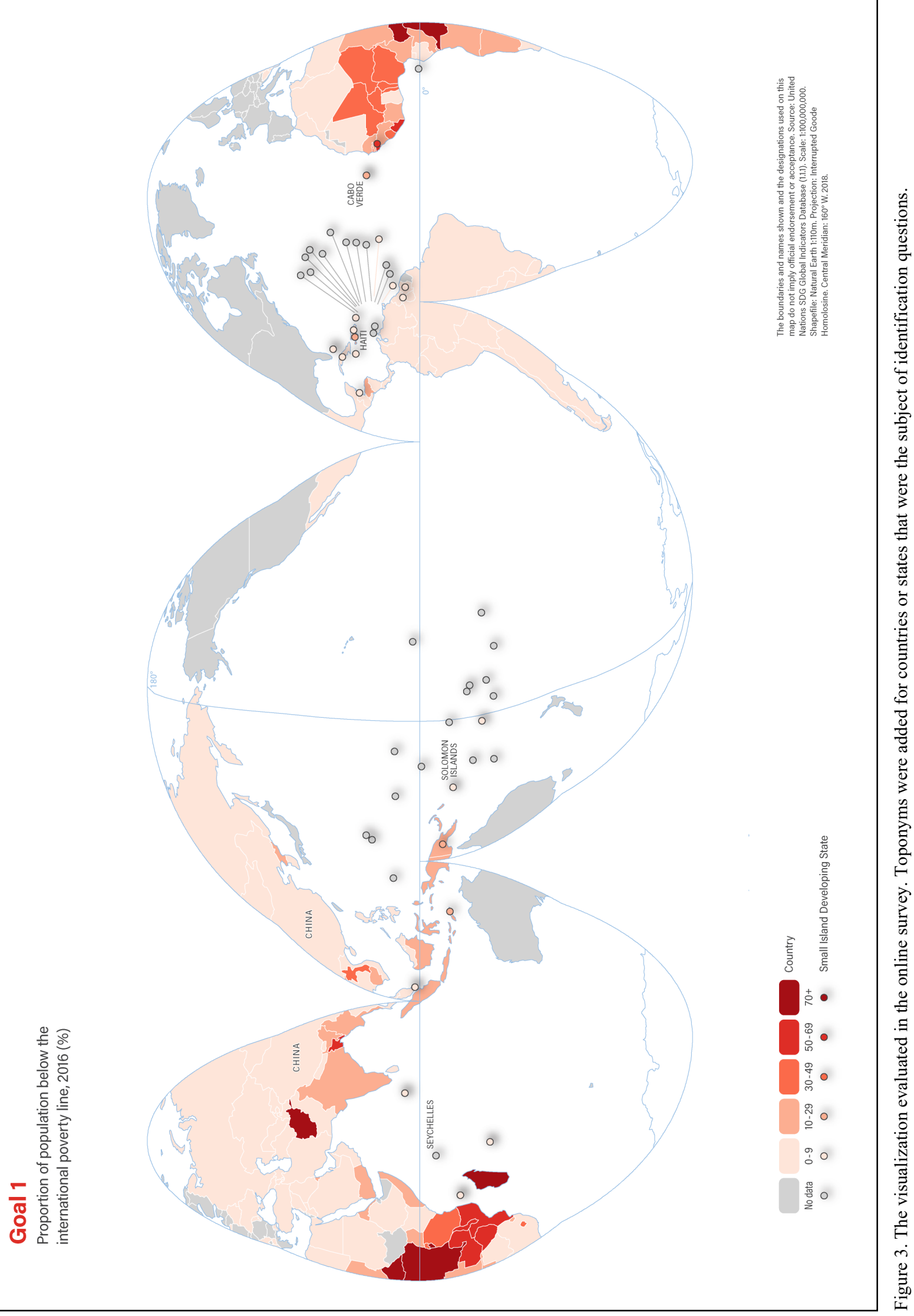

Proceedings of the International Cartographic Association, 2, 2019.

29th International Cartographic Conference (ICC 2019), 15-20 July 2019, Tokyo, Japan. This contribution underwent

single-blind peer review based on submitted abstracts. https://doi.org/10.5194/ica-proc-2-40-2019| (๔ Authors 2019. CC BY 4.0 License. 
unfamiliar and would likely require a chart to match the code with the country name.

Based on the conversations in the first focus group, Maps $\mathrm{C}$ and $\mathrm{D}$ were revised and shown to Focus Group 2. Five of the six participants in the second focus group preferred Map D for its use of a single map to show the distribution of data. One participant wanted to see an example of a single map in an uninterrupted projection. When ISOalpha3 codes were proposed in Focus Group 2, this representation was not supported. The interviewee from a small island developing state appreciated that each circle representing an island did not overlap in the Caribbean.

\subsection{Online survey}

For the online survey, participants were presented a map displaying SDG Indicator 1.1.1, the global distribution of poverty. Participants performed a series of tasks (identify, compare, overview) to assess the effectiveness of the map to visualize SIDS and non-SIDS data. Satisfaction and qualitative questions about the design were also asked. The online survey posed a series of 15 questions that were multiple choice, Likert scale and open ended.

Ninety-four responses were collected in the online evaluation, though only 76 participants fully completed the

\section{Highest degree obtained \\ in a geographic-related science}

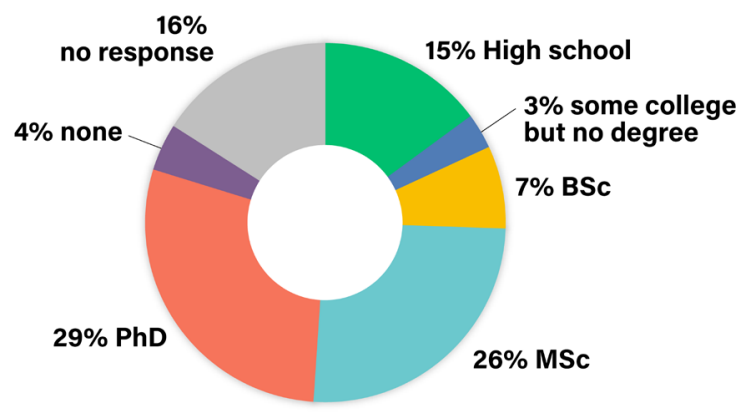

\section{Experience with small island states}

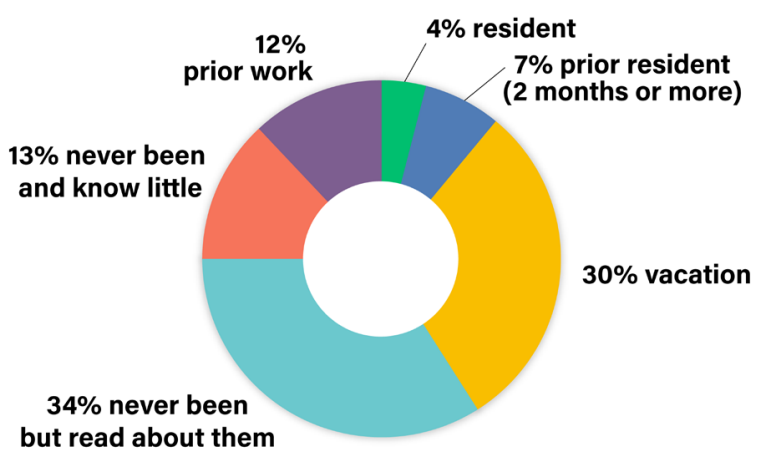

Figure 5. Education and experience of survey participants. Geographic-related education was noted by 79 of 94 participants. All 94 participants shared their experience with small island states.

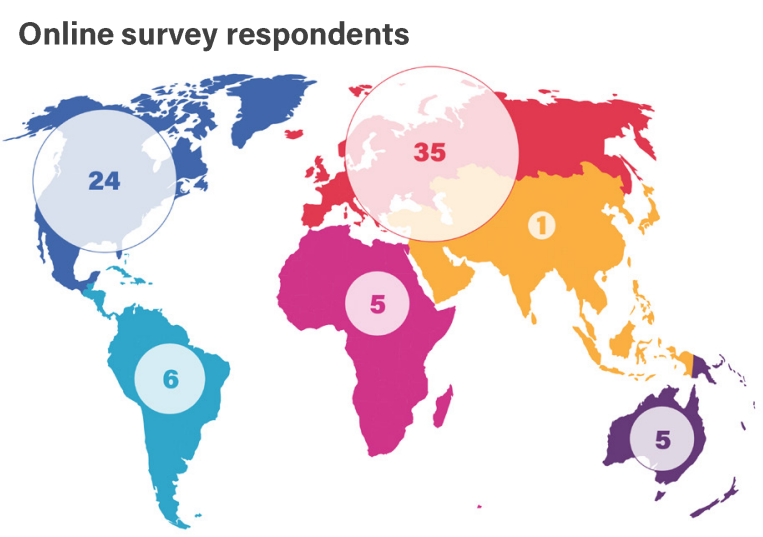

Figure 4. Nationalities were provided by 76 of 94 participants.

survey (Figure 4). Reported representation from SIDS included the Seychelles (2), Puerto Rico (1) and Saint Vincent and the Grenadines (1). Fifty-percent of respondents $(n=79)$ had worked at an international organization. Respondents $(n=78)$ were $36 \%$ female and $63 \%$ male; $1 \%$ preferred not to specify. Participants indicated their highest degree obtained in a geographicrelated science and experience with small island states (Figure 5).

Eighty percent of responses correctly identified available and unavailable data of SIDS whereas the poverty rate for a larger nation, such as China, was correctly identified by $86 \%$ of the participants. In comparing two SIDS, most participants $(96 \%)$ correctly answered that Haiti (in the Caribbean) had a higher rate of poverty than the Solomon Islands (in the Pacific). In response to the region of the world that had countries with higher poverty rates than the SIDS in the Caribbean, most respondents (93\%) correctly answered Central Africa. Sixty-five percent of the participants correctly estimated the percentage of SIDS without data in the Pacific. Half of the participants correctly estimated the percentage of all countries without data world-wide. In general, participants rated the identification questions as easier than comparison or overview questions (Figure 6).

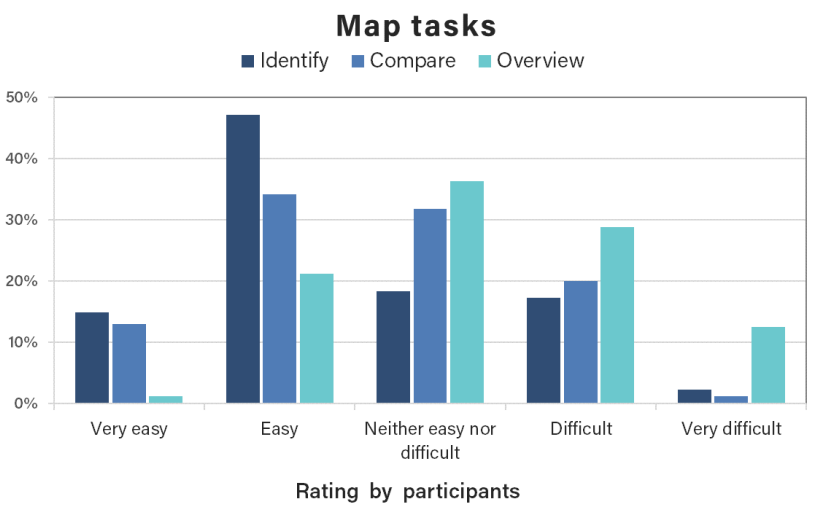

Figure 6. Participants' rating of map tasks. Identification tasks were rated by 87 of 94 respondents. Comparison tasks were rated by 85 of 94 respondents. Overview tasks were rated by 80 of 94 respondents. 
Most participants $(n=79)$ thought the visualization was appropriate to show available and unavailable data for SIDS with $13 \%$ strongly agreeing and $54 \%$ agreeing. Others neither agreed nor disagreed (8\%), disagreed (20\%) or strongly disagreed $(5 \%)$ that the visualization was appropriate. Respondents $(n=78)$ were split in terms of the appropriateness of the visualization for all countries with $5 \%$ strongly agreeing, $40 \%$ agreeing, $18 \%$ neither agreeing nor disagreeing, 31\% disagreeing and 6\% strongly disagreeing it was appropriate.

Participants $(n=49)$ provided impressions of the visualization in an open comments section. Responses were thematically coded and organized in five overarching categories of positive, neutral, negative, adjustment and additional suggestions. These were established after reading user comments.

Most responses contained multiple themes and therefore assigned multiple codes to correspond to each identified theme. Positive comments mentioned support of the projection (9), design (6), study or concept (2), central meridian in Pacific (2), color (2), symbology (3) and drop shadow near points representing SIDS (1). Neutral responses noted it was a new or unfamiliar projection (9) and the color seemed fine (4). Negative responses included comments disliking the projection (5) and expressing difficulty seeing an overview of the world or continents (4) as well as disliking the drop shadow near points representing SIDS (2) or symbology (1). Adjustment comments were suggestions regarding the color (16), enlarging the points representing SIDS (11), adjusting drop shadows near the points representing SIDS (5), changing the projection (7), experimenting with the unavailable data symbology (2) and adjusting the map scale (4). Addition comments included recommendations to label all SIDS (4) or oceans (1) as well as to provide interactivity (6) such as zoom and hover functionality.

\section{Discussion}

There were several noteworthy findings related to the projection, symbolization and colors selected for the visualization. Most participants $(67 \%)$ thought the approach was appropriate to display the data of small island developing states in a world map. Comments related to the Interrupted Goode Homolosine projection varied in the survey from supportive (9) to noting it was unfamiliar (9) to suggesting it should be changed (7) to expressing dislike because it was unfamiliar or splits (5). Responses to the projection were concurrent with differing views on using non-continuous map projections, and the tension between reducing distortion and introducing discontinuities (Canters, 2002). Despite the projection's focus on ocean regions, participants were able to identify and compare countries and regions split by the map. Though, less support was expressed for the visualization to display non-island data with only $45 \%$ strongly agreeing or agreeing with this statement.

Nearly all participants accepted circular point symbols without comment, suggesting it was an intuitive solution to represent small island data in choropleth world maps. However, the survey tool reduced the map to less than the width of the browser, which reduced the size of points representing SIDS and contributed to the challenge in distinguishing color values. Some participants described difficulty differentiating between the first two lighter classes, while others had trouble perceiving the difference between the gray of no data and one of the two lighter classes, or even both. This was confirmed by the incorrect answers to SIDS identification questions. In hindsight, a sequential, multi-hue color scheme via ColorBrewer might have provided more distinction.

Even though $80 \%$ of participants correctly answered SIDS identification questions and $80 \%$ did not note difficulty in answering identification questions, the five-class color scale added visual complexity to the map. Interestingly, when users compared two values of SIDS, 96\% correctly differentiated the lightest and second lightest classes. While there were two possible answers for the comparison question, relative to seven potential responses for identification questions, it did require differentiation of both lighter colors. It is possible surrounding island values eased this comparison task.

Narrowing the classes from five to three would make the colors more distinctive, as well as provide regional and global overviews of SIDS data since three classes permits selectivity in point symbols (Bertin, 1983). In this regard, three classes would be suitable for a visualization without toponyms. Toponyms would likely be required for identification of SIDS even with geographic knowledge of island regions.

Challenges identified in this study could be addressed through an interactive visualization. For example, the user might be able to move the central meridian or shift between the Interrupted Goode Homolosine projection focused on oceans to one focused on landmasses. Selected views might zoom to island regions or a lens could magnify an area for closer inspection. Islands could be identified through a search tool or tooltip.

\section{Conclusion}

Small island developing states are recognized by the United Nations for their social, economic and environmental vulnerabilities. Yet, due to their size, SIDS can be overlooked in maps tracking progress towards reaching SDGs. Of the five proposed visualizations, the Interrupted Goode Homolosine projection was selected based on expert feedback and tested in an online survey. Eighty-percent of online survey respondents could identify a point value representing available and unavailable data of SIDS. Ninety-six percent of participants correctly compared SIDS values. This suggests that the map can be used to identify and compare values of specific islands, though it is likely that labeling would be required. However, participants had more difficulty estimating the percentage of SIDS missing data within a region and within the world-wide context, meaning the map would not be suitable to provide regional or global overviews in its current format.

Point symbols combined with the Interrupted Goode Homolosine projection focused on oceans enhances the visualization of SIDS data. Nearly seventy percent of 
survey respondents, predominately from North America and Europe, were supportive of the map's appropriateness to visualize indicator data of SIDS. This study offers approaches to increase the perceptibility of SIDS in static, small-scale choropleth maps and contributes to the visualization of global status towards reaching Sustainable Development Goals.

\section{References}

AOSIS. (2018). Alliance of Small Island States (AOSIS). Retrieved May 2, 2018, from http://aosis.org/

Bertin, J. (1983). Semiology of graphics: Diagrams, networks, maps. (Translated by W.J. Berg, Ed.). Madison, WI: The University of Wisconsin Press.

Canters, F. (2002). Small-scale map projection design. London: Taylor \& Francis.

DESA - UN. (2018a). The Sustainable Development Goals Report 2017. Retrieved April 4, 2018, from https://undesa.maps.arcgis.com/apps/MapSeries/index. html?appid=9f608346a69644c387ddc9df29f12b43

DESA - UN. (2018b). UN Sustainable Knowledge Platform: Small Island Developing States. Retrieved April 11, 2018, from https://sustainabledevelopment.un.org/topics/sids/list

Everest-Phillips, M. (2014). Small, so simple? Complexity in Small Island Developing States. Singapore: United Nations Development Programme (UNDP) Global Centre for Public Service Excellence.

Kinkeldey, C., MacEachren, A. M., Riveiro, M., \& Schiewe, J. (2017). Evaluating the effect of visually represented geodata uncertainty on decision-making: systematic review, lessons learned, and recommendations. Cartography and Geographic Information Science, 44(1), 1-21. https://doi.org/10.1080/15230406.2015.1089792

Kinkeldey, C., MacEachren, A. M., \& Schiewe, J. (2014). How to assess visual communication of uncertainty? A systematic review of geospatial uncertainty visualisation user studies. The Cartographic Journal, 51(4), 372-386. https://doi.org/10.1179/1743277414Y.0000000099

Kraak, M. J., \& Ormeling, F. (2003). Cartography: Visualization of geospatial data (Second). Essex: Pearson Education Limited.

Krygier, J., \& Wood, D. (2005). Making maps: a visual guide to map design for GIS. New York, NY: The Guilford Press.

Nurse, L. A., McLean, R. F., Agard, J., Briguglio, L. P., Duvat-Magnan, V., Pelesikoti, N., ... Webb, A. (2014). Small islands. In V. R. Barros, C. B. Field, D. J. Dokken, M. D. Mastrandrea, K. J. Mach, T. E. Bilir, ... L. L. White (Eds.), Climate Change 2014: Impacts, Adaptation, and Vulnerability. Part B: Regional Aspects. Contribution of Working Group II to the Fifth Assessment Report of the Intergovernmental Panel on Climate Change (pp. 1613-1654). Cambridge: Cambridge University Press.
OHRLLS - UN. (2018). About the Small Island Developing States. Retrieved from http://unohrlls.org/about-sids/\%0A

Osiris. (2013). SIDS map. Retrieved April 28, 2018, from https://commons.wikimedia.org/wiki/File:SIDS_map_e n.svg

Pelling, M., \& Uitto, J. (2001). Small island developing states: natural disaster vulnerability and global change. Global Environmental Change Part B: Environmental Hazards, 3(2), 49-62. https://doi.org/10.1016/S14642867(01)00018-3

Roth, R. E. (2013). An empirically-derived taxonomy of interaction primitives for interactive cartography and geovisualization. IEEE Transactions on Visualization and Computer Graphics, 19(12), 2356-2365. https://doi.org/10.1109/TVCG.2013.130

Roth, R. E., Ross, K., \& MacEachren, A. (2015). UserCentered design for interactive maps: A case study in crime analysis. ISPRS International Journal of GeoInformation, 4(1), 262-301. https://doi.org/10.3390/ijgi4010262

Smith Mason, J., Retchless, D., \& Klippel, A. (2017). Domains of uncertainty visualization research: a visual summary approach. Cartography and Geographic Information Science, 44(4), 296-309. https://doi.org/10.1080/15230406.2016.1154804

UNSD. (2018). Methodology: Standard country or area codes for statistical use (M49) - Small Island Developing States. Retrieved May 31, 2018, from https://unstats.un.org/unsd/methodology/m49/\#sids

World Bank. (2017). Atlas of Sustainable Development Goals 2017: World Development Indicators. https://doi.org/10.1596/978-1-4648-1080-0 